\title{
The Arctic Guide: Wildlife of the Far North
}

By Sharon Chester. 2016. Princeton University Press. 544 pages, 27.95 USD, 22.95 GBP, Paper.

The Arctic is often seen as a vast wilderness, or even a frozen wasteland, that could only support a small number of living things, such as Polar Bears (Ursus maritimus) and Reindeer (Rangifer tarandus). Yet in The Arctic Guide, Sharon Chester gives a wonderful overview of the diversity of life in the Arctic and truly demonstrates that the Arctic has a plethora of incredible organisms living there. The Arctic Guide is formatted like most standard field guides, with hundreds of pages of species descriptions, distribution maps, and colour plates for identification. However, unlike most field guides, The Arctic Guide covers a very wide range of taxa, including plants, some insects, and all vertebrate fauna. And even with this large volume of fauna and flora, the guide is still relatively compact and can easily fit in a small backpack with other essential field gear. Not only does The Arctic Guide cover a wide range of taxa, but it also covers a wide geographic range, including all eight countries that lie within the Arctic Circle. Overall, this guide is an excellent overview of Arctic biodiversity for new Arctic travellers interested in biodiversity.

Author Sharon Chester is a wildlife photographer, illustrator, and naturalist who has written several other books about wildlife and natural history, including $A$ Wildlife Guide to Chile (2008, Princeton University Press) and Antarctic Birds and Seals (1993, Wandering Albatross). She has spent a lifetime learning about the natural world and has thoroughly researched the wildlife presented in this guide. She even provides common names in multiple languages, including local indigenous languages.

An important criticism of this book is that it covers far too many species to go into proper detail for species identification. The small amount of text and single image for most species are not sufficient to differentiate between similar species. This is especially apparent for small mammals, such as shrews and voles. Experienced naturalists should use an appropriate taxa-specific guide for more details about species identification. Similarly, not all scientific names are correct. The author states that scientific names were up-to-date at the time of writing, but may have become out of date during the publication process. Yet some names are more than 10 years out of date at the time of publication. For example, the Wood Frog is called Rana sylvatica in the text, yet it has been known as Lithobates sylvaticus since 2006 (Crother 2012). Readers interested in up-to-date scientific names should look in taxa-specific reference materials.

The author introduces the Arctic with an overview of different definitions of where the Arctic begins (such as the Arctic Circle $\left[66^{\circ} 34^{\prime} \mathrm{N}\right]$ and the tree line), as well as common physical features and zones within the Arctic. This is a very useful section that can help a firsttime visitor to the Arctic understand the region. Despite this very clear introduction to what the Arctic is, the author doesn't seem to stick to any given definition when including different species in this book. Species from the boreal and taiga ecozones are included in the guide if they live past the Arctic Circle, and are discussed as much as species that are found only in the Arctic. Perhaps less emphasis should be placed on these sub-Arctic species. Similarly, for species with more southerly distributions, information is presented that is only specific to populations living in the southern extent of their range. For a book focussed on species of the Arctic, the information presented for these species should be specific to populations that live in the Arctic.

The author made a small attempt to include invertebrates in this guide with the section on flies, bees, and butterflies. However, most of this section focuses on butterflies: 3.5 pages were devoted to flies and bees and 20.5 pages to butterflies. Either the chapter could have just focussed on butterflies or more information should have been presented on the other insects. Moreover, this section represents only a small fraction of invertebrate taxa in the Arctic, so justification is needed for the exclusion of other invertebrate taxa. A similar criticism can be made for the section on flora. It is introduced as a section on plants, but then spends 10 pages discussing cyanobacteria, mushrooms, and lichens. This section should therefore be titled a bit more broadly.

Despite these criticisms, The Arctic Guide is an excellent introduction for those interested in a wide range of taxa, so long as they are not looking for detailed species accounts or identification information. Then again, a guide covering this same wide range of taxa across the entire Arctic that also included detailed identification features and keys would be at least twice the size, which would remove its current utility as a portable field guide. I would recommend this guide to any naturalists traveling to the Arctic for the first time as a broad overview of the biodiversity that they might encounter.

\section{Literature Cited}

Crother, B. I. 2012. Scientific and Standard English Names of Amphibians and Reptiles of North America North of Mexico, with Comments Regarding Confidence in our Understanding. Seventh edition. Society for the Study of Amphibians and Reptiles Herpetological Circular 39.

\section{WiLliam D. HALLIDAY}

Wildlife Conservation Society Canada, Whitehorse, YT, and Department of Biology, University of Victoria, Victoria, BC, Canada 